\title{
Erratum to: A biological tissue adhesive and dissolvent system for intraocular tumor plaque radiotherapy: an in vivo animal model experiment
}

\author{
Ofira Zloto $^{1} \cdot$ Dror Alezra $^{2}$ - Oded Sagiv ${ }^{1} \cdot$ Michael Belkin $^{1}$. \\ Vicktoria Vishnevskia Dai ${ }^{1}$ - Iris Moroz ${ }^{1}$ Gahl Greenberg ${ }^{3}$ - Elad Ben-Artsi ${ }^{1}$. \\ Ido Didi Fabian ${ }^{1,4}$
}

Published online: 29 August 2015

(C) Springer-Verlag Berlin Heidelberg 2015

Erratum to: Graefes Arch Clin Exp Ophthalmol (2015)

DOI 10.1007/s00417-015-3082-3

Reason: Missing acknowledgement

Acknowledgement: This study was supported by a grant from the Claire and Amedee Maratier Institute for the Study of Blindness and Visual Disorders, Sackler Faculty of Medicine, Tel-Aviv University.

The online version of the original article can be found at http://dx.doi.org/ 10.1007/s00417-015-3082-3.

$\triangle$ Ido Didi Fabian

didifabian@gmail.com

1 Goldschleger Eye Institute, Sheba Medical Center, Sackler Faculty of Medicine, Tel Aviv University, Tel Aviv, Israel

2 Department of Radiation Oncology, Sheba Medical Center, Sackler Faculty of Medicine, Tel Aviv University, Tel Aviv, Israel

3 Department of Diagnostic Imaging, Sheba Medical Center, Sackler Faculty of Medicine, Tel Aviv University, Tel Aviv, Israel

4 Dr. Pinchas Borenstein Talpiot Medical Leadership Program 2012, Tel Hashomer, Israel 